\title{
Design Optimization for Shear Key on the TF Coil Structure of the KSTAR Tokamak
}

\author{
D. S. Lee, ${ }^{\mathrm{a}, 1}$ Y. D. Kwon, ${ }^{\mathrm{b}}$ and J. S. Han ${ }^{\mathrm{c}}$
}

${ }^{a}$ Division of Computer Aided Mechanical Engineering, Yeungjin College, Daegu, Republic of Korea

${ }^{\mathrm{b}}$ Department of Mechanical Engineering, Kyungpook National University, Daegu, Republic of Korea

${ }^{c}$ Graduate School, Kyungpook National University, Daegu, Republic of Korea

${ }^{1}$ dslee@yjc.ac.kr

The KSTAR tokamak is comprised of a magnet system, vacuum vessel, and cryostat, thereby facilitating vacuum conditions for plasma gas at high temperatures, along with low-temperature helium gas for cooling. The TF coil structure, a part of the magnet system, is constructed and jointed with 16 pieces at 22.5-degree intervals using a conical bolt and shear key. The main function of the shear key in the inner and outer inter-coil structures is to resist in-plane and out-of-plane forces and to increase the shear stiffness for the inter coil structures. However, since the shape of the shear key is difficult to produce and can incur high costs, the shear key needs to be dimensionally optimized to regularize the stress between the key and the structure. Accordingly, shape optimization of the shear key was carried out using the Taguchi method and the stresses analyzed by ANSYS.

Keywords: KSTAR, Taguchi method, optimization, shear key, TF coil structure.

Introduction. The development of nuclear fusion is becoming the main energy of the future. As part of this process, plasma needs to be sealed at an ultrahigh temperature in a fixed space for $1 \mathrm{~s}$. The sealed space is called Tokamak that is a device sealing up plasma as sending an electric current to the plasma existing a powerful magnetic field and at Tokamak's center to prevent fusing due to contact with the plasma. Korea is currently constructing a nuclear fusion power plant on the basis of Korea Superconducting Tokamak Advanced Research (KSTAR) [1-3]. The toroidal field (TF) coil structure of the KSTAR tokamak is D-shaped, with a size of $4.2 \mathrm{~m} \times 3 \mathrm{~m} \times 22.5^{\circ}$ (height width angle), and assembled into a total of 16 fan-shapes. The inner and outer inter-coil are joined at the top and bottom, and shear key $[4,5]$ used to support the shear force in terms of gravity and set assembling datum, as shown in Fig. 1.

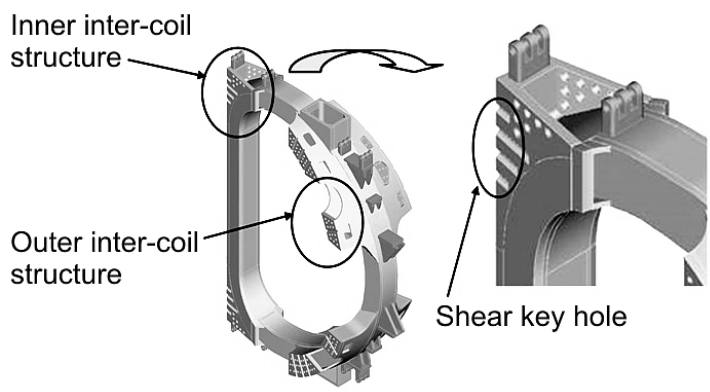

Fig. 1. The shape of TF coil structure for KSTAR.

Thus, this paper fixes the design factors for optimizing the shape of the shear key and selects models to perform a finite element analysis $[6,7]$ with an orthogonal array, plus CATIA is used for the modeling, ANSYS for the finite element analysis, and the Taguchi method for the optimization and statistical analysis. 


\section{Optimization of Shear Key.}

The Taguchi Method [8, 9]. A table of an orthogonal array has been used for efficient design in a discrete design space, and it can produce similar results to the trial and error method (one-factor-at-a-time) with a small size experiment by combining the factors used to design the experiment. Therefore, this paper used a table of an orthogonal array to optimize the shape of the shear key, determine the target optimum conditions, and evaluate the stability of these conditions. Circular and rectangular shapes are known to reduce the maximum stress of the shear key. Thus, the table initially covered five kinds of the factor, including the shape of the shear key and two kinds of level. Yet, since it was impossible to obtain the optimal conditions due to the influence of the same interaction for each different shape of the shear key, the shear key was optimized for each shape according to the strength of the shape and convenience of productivity. Thus, final factors and levels are shown in Table 1. In this paper, each shape has four kinds of the factor and two kinds of level.

$\mathrm{T}$ a $\mathrm{b} 1 \mathrm{e} 1$

Factors and Levels

\begin{tabular}{|c|c|c|c|}
\hline \multicolumn{2}{|c|}{ Factor } & \multicolumn{2}{c|}{ Level } \\
\cline { 3 - 4 } \multicolumn{2}{|c|}{} & 1 (left side) & 2 (right side) \\
\hline A & Key hole & Exist & Nothing \\
\hline B & Material & Inconel 718 & Brass \\
\hline C & Aspect ratio & $1: 1$ & $1: 0.8$ \\
\hline D & Fillet of flange & Exist & Nothing \\
\hline E, F, G & Error effect & - & - \\
\hline
\end{tabular}

The table of the orthogonal array used was $L_{8}\left(2^{7}\right)$. The level of the design factors was determined based on the initial design factors, then each matrix from the table of the orthogonal array tested, resulting in a corresponding objective function. Then, a characteristic value was identified using the characteristic function accorded to the objective function. After that, the optimum design value was determined through a mean analysis based on the characteristic function and compared with the value for each matrix tested. To select the optimum level, the effects of different design factors on the design values were evaluated, and the statistical analysis used the signal-to-noise ratios. Taguchi defined several signal to noise ratios, according to the performance characteristics. The signal to noise ratio, a value induced from a quality loss function assigned with a second-order formula, is a measure that considers both the mean and the distribution of the performance characteristics. In this paper, the maximum stress that appears at the shear key is a smaller-the-better characteristic. Thus, the signal-to-noise was performed according to a smaller-the-better type analysis.

$$
\text { Smaller-then-better type: } S / N=-10 \log _{10}\left(\frac{1}{n} \sum_{i=0}^{n} y_{i}^{2}\right) \text {, }
$$

where $n$ is the frequency of the repeated measurements under a combination of similar control factors and $y_{i}$ is the value of each measurement to perform the finite element analysis. Thus, the design factor conditions that maximized the signal-to-noise ratio were found by considering the objective function of the characteristic value on the table of the orthogonal array. As a result, the design factor conditions that produced a small variation in the performance characteristics under noise and the mean were identified using the 
objective function. This paper also determined the design factor conditions where the objective function was the maximum stress obtained from the shear key, the characteristic value on the table of the orthogonal array, and the mean was the minimum. Plus, the significant design factors were determined based on a $95 \%$ confidence interval using ANOVA (analysis of variation). To validate the optimization conditions, the optimized final model according to the Taguchi method was performed using a finite element analysis. Finally, it can be conformed the reappearance for signal-to-noise ratio.

Design Factors. For the TF coil structure, the shear key [10] is the datum for assembling with inner and outer inter-coil structure and is supported shear force in terms of gravity. Optimizing its shape is important because the TF coil structure's shear key has many spatial limitations. Figure 2 shows a cross-section of the TF coil structure, while Table 2 shows the grade and properties of the material used in the TF coil structure.

$\mathrm{T}$ a b 1 e 2

Section Drawing of TF Coil Structure

\begin{tabular}{|c|c|c|c|c||}
\hline No. & Part name & Material & $\begin{array}{c}\text { Young modulus } \\
(\mathrm{MPa})\end{array}$ & $\begin{array}{c}\text { Poisson's } \\
\text { ratio }\end{array}$ \\
\hline 1 & Inner inter-coil structure & $\mathrm{JJ} 1$ & $1.86 \cdot 10^{5}$ & 0.280 \\
\hline 2 & Outer inter-coil structure & $\mathrm{JJ} 1$ & $1.86 \cdot 10^{5}$ & 0.295 \\
\hline 3 & Shear key & Inconel 718 & $2.11 \cdot 10^{5}$ & 0.295 \\
\cline { 2 - 5 } & & Brass & $1.06 \cdot 10^{5}$ & 0.292 \\
\hline
\end{tabular}

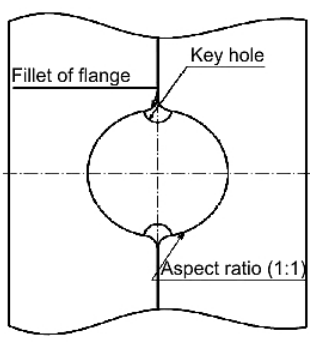

a

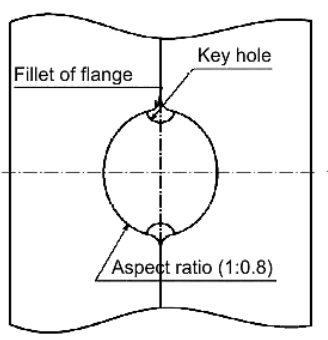

b

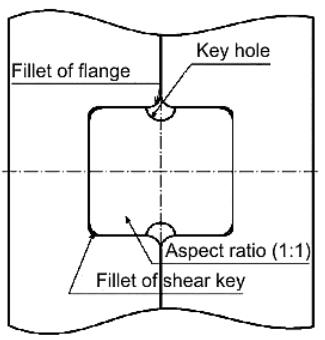

$\mathrm{c}$

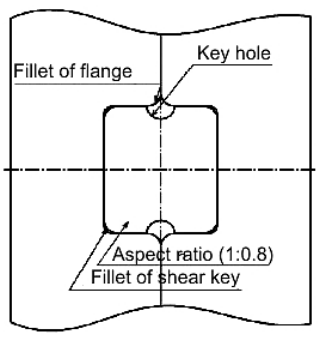

d

Fig. 2. Section drawing for design factors of circular type shear key and rectangular type shear key.

The sample structures made according to the table of the orthogonal array were subjected to a finite element analysis and analyzed for their maximum stress. The boundary condition gave a load of $1 \mathrm{MN}$ with the shear force in terms of the gravity of the structure. The contact condition between the parts was used as the surface-to-surface [10-14]. In the finite element analysis (FEA), the main assumption was the conical bolt and a lot of the bolts were tightened in the structure, and in the case of the circular-type shear key, when it gave the shear force in terms of gravity, the structure was not allowed to open at the circle line and additional pre-tension occurred at the conical bolt, plus a lot of bolts was not allowed.

Optimization of Circular-Type Shear Key. Table 3 shows the results of the FEA for eight models of a circular shear key (see Fig. 2a, b) when using an orthogonal array.

At this table, converted stresses of shear key mean the stress that multiplied the calculated stress by the ratio of yield stress $\left(\sigma_{y, \text { Inconel }} / \sigma_{y, \text { brass }} \approx 2.3\right)$ between brass and 
$\mathrm{T}$ a b 1 e 3

The Result of FEA by Using Orthogonal Array

\begin{tabular}{||c|c|c|c|c|c||}
\hline No. & Key hole & Material & Aspect ratio & Fillet of flange & Converted stress (MPa) \\
\hline$\# 1$ & $R=5 \mathrm{~mm}$ & Inconel & $1: 1$ & $R=5 \mathrm{~mm}$ & 344 \\
\hline$\# 2$ & $R=5 \mathrm{~mm}$ & Inconel & $1: 1$ & No & 237 \\
\hline$\# 3$ & $R=5 \mathrm{~mm}$ & Brass & $1: 0.8$ & $R=5 \mathrm{~mm}$ & 2699 \\
\hline$\# 4$ & $R=5 \mathrm{~mm}$ & Brass & $1: 0.8$ & No & 2529 \\
\hline$\# 5$ & No & Inconel & $1: 0.8$ & $R=5 \mathrm{~mm}$ & 848 \\
\hline$\# 6$ & No & Inconel & $1: 0.8$ & No & 497 \\
\hline$\# 7$ & No & Brass & $1: 1$ & $R=5 \mathrm{~mm}$ & 386 \\
\hline$\# 8$ & No & Brass & $1: 1$ & No & 280 \\
\hline \hline
\end{tabular}

T a b 1 e 4

\section{Optimum Shape of the Rounding Shear Key}

\begin{tabular}{|c|c|c|c||}
\hline \multicolumn{2}{|c|}{ Factor } & Optimized model & Level \\
\hline A & Key hole & No & 2 \\
\hline B & Material & Inconel 718 & 1 \\
\hline C & Aspect ratio & $1: 1$ & 1 \\
\hline D & Fillet of flange & No & 2 \\
\hline
\end{tabular}

T a b 1 e 5

The Results of FEA

\begin{tabular}{|c|c|}
\hline Item & Shear key \\
\hline Model \# 8 & $140 \mathrm{MPa}$ \\
\hline Optimized model & $137 \mathrm{MPa}$ \\
\hline
\end{tabular}

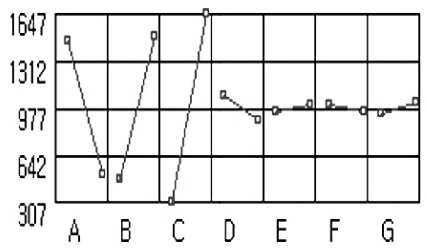

Fig. 3. Illustration of design factor effect.

Inconel to consider similar stress condition. When comparing the $S / N$ ratio for the stress calculated using the orthogonal array (Table 3), the results are shown in Fig. 3. As a result of the ANOVA analysis of the interaction for each design factor of a circular shear key, the percentage contribution left much to be desired and is the design factors were found to be independent of each other.

Table 4 shows the optimum shape model for the shear key as regards the smaller-thebetter type value based on the effect of the design factors (Fig. 3).

An FEA of the shear key model was also performed, and the model with the minimum stress for the shear key compared with the samples in the orthogonal array (see Table 5).

The FEA results for the optimized circular shear key are shown in Fig. 4. 


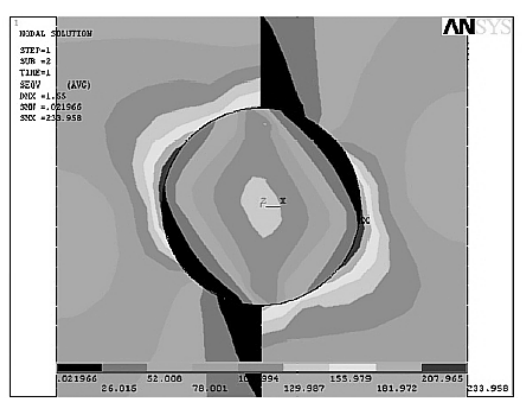

a

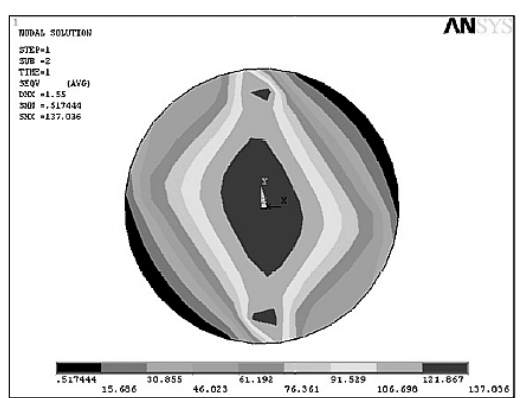

$\mathrm{b}$

Fig. 4. FEA result of the optimized shear key structure (a); FEA result of the optimized shear key (b).

FEA Optimization of Rectangular-Type Shear Key. Table 6 shows the results of the FEA for eight models with a rectangular shear key (see Fig. 4c, d) when using an orthogonal array.

As the circular-type shear key, converted stresses of shear key mean the stress that multiplied the calculated stress by the ratio of yield stress $\left(\sigma_{y \text {, Inconel }} / \sigma_{y, \text { brass }} \approx 2.3\right)$ between brass and Inconel to consider similar stress condition. From Table 6, after comparing $S / N$ ratio for the stress calculated using the orthogonal array, the results are shown in Fig. 5.

T a b 1 e 6

The Result of FEA by Using Orthogonal Array

\begin{tabular}{||c|c|c|c|c|c||}
\hline No. & Key hole & Material & Aspect ratio & Fillet of flange & Converted stress (MPa) \\
\hline$\# 1$ & $R=5 \mathrm{~mm}$ & Inconel & $1: 1$ & $R=5 \mathrm{~mm}$ & 372 \\
\hline$\# 2$ & $R=5 \mathrm{~mm}$ & Inconel & $1: 1$ & No & 751 \\
\hline$\# 3$ & $R=5 \mathrm{~mm}$ & Brass & $1: 0.8$ & $R=5 \mathrm{~mm}$ & 855 \\
\hline$\# 4$ & $R=5 \mathrm{~mm}$ & Brass & $1: 0.8$ & No & 1586 \\
\hline$\# 5$ & No & Inconel & $1: 0.8$ & $R=5 \mathrm{~mm}$ & 322 \\
\hline$\# 6$ & No & Inconel & $1: 0.8$ & No & 275 \\
\hline$\# 7$ & No & Brass & $1: 1$ & $R=5 \mathrm{~mm}$ & 777 \\
\hline$\# 8$ & No & Brass & $1: 1$ & No & 611 \\
\hline
\end{tabular}

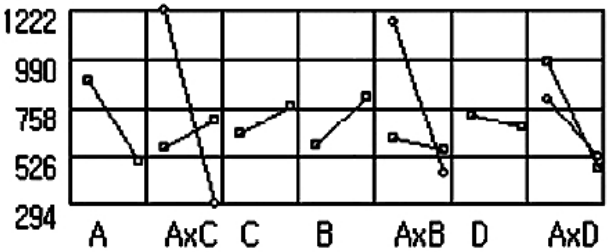

Fig. 5. Illustration of design factor effect $(A \times B / A \times C / A \times D$ : interaction $)$.

As a result of the ANOVA analysis of the interaction for each design factor of a rectangular shear key, an effective interaction (42.7\%) was found between the key hole and the aspect ratio. But interactions between the key hole and the material, between the key and fillet of the flange were ignored due to low percentage contribution. Thus, the key hole 
and aspect ratio were found to be interdependent, while the other two variables were independent. Table 7 shows the optimum shape model for the rectangular shear key as regards the smaller-the-better type value based on the effect of the design factors (Fig. 5).

An FEA of the shear key model was also conducted, as shown in Table 7, and the model with the minimum stress for the shear key was the same with sample \# 6 in orthogonal array (see Table 8).

$\mathrm{T}$ a b 1 e 7

Optimum Shape of the Rectangular Shear Key

\begin{tabular}{|c|c|c|c|}
\hline \multicolumn{2}{|c|}{ Factor } & \multirow{2}{*}{$\begin{array}{c}\text { Optimized model } \\
\text { No }\end{array}$} & \multirow{2}{*}{$\begin{array}{c}\text { Level } \\
2 \\
\end{array}$} \\
\hline A & Key hole & & \\
\hline B & Material & Inconel 718 & 1 \\
\hline $\mathrm{C}$ & Aspect ratio & $(1: 1) \rightarrow$ Not use & 1 \\
\hline $\mathrm{D}$ & Fillet of flange & No & 2 \\
\hline \multirow[t]{2}{*}{$\mathrm{A} \times \mathrm{B}$} & Key hole & \multirow{2}{*}{$\begin{array}{c}\text { Neglect due to } \\
\text { low \% contribution }\end{array}$} & \multirow[t]{2}{*}{-} \\
\hline & Material & & \\
\hline \multirow[t]{2}{*}{$\mathrm{A} \times \mathrm{C}$} & Key hole & No & 2 \\
\hline & Aspect ratio & 1:0.8 & 2 \\
\hline \multirow[t]{2}{*}{$A \times D$} & Key hole & \multirow{2}{*}{$\begin{array}{c}\text { Neglect due to } \\
\text { low } \% \text { contribution }\end{array}$} & \multirow[t]{2}{*}{-} \\
\hline & Fillet of flange & & \\
\hline
\end{tabular}

$\mathrm{T}$ a $\mathrm{b} 1$ e 8

The Results of FEA

\begin{tabular}{|c|c|}
\hline Item & Shear key \\
\hline Optimized model $($ model \# 6) & $275 \mathrm{MPa}$ \\
\hline
\end{tabular}

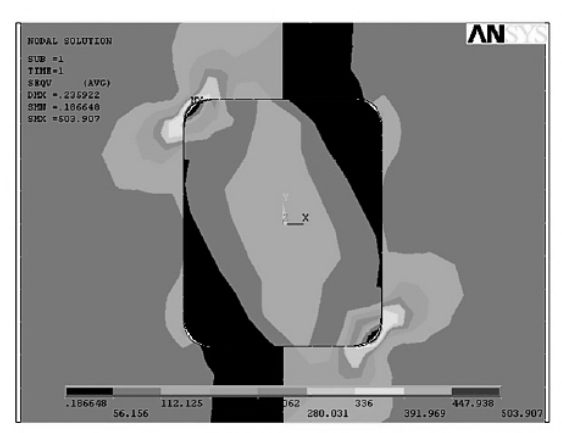

a

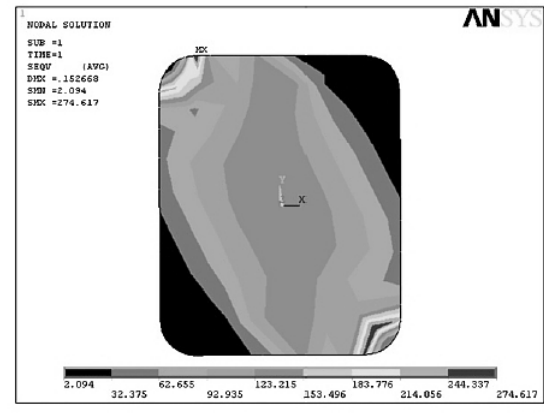

$\mathrm{b}$

Fig. 6. FEA result of the optimized shear key structure (a); FEA result of the optimized shear key (b).

The FEA results for the optimized rectangular shear key are shown in Fig. 6.

From the FEA results, the stress of the rectangular shear key was $200.7 \%$ higher compared to the circular shear key (circular/rectangular $=137 \mathrm{MPa} / 275 \mathrm{MPa}$ ). When the shear force of the circular shear key occurred due to the weight between inter-coil structures, the shear force was generated in the circumference direction and caused a gap between the inter-coil structures. Especially, the conical bolt joining the TF coil structure had the potential to be over-supported by pre-tension. While it is difficult to manufacture a 
semicircular shaped inter-coil structure, a rectangular shear key can be easily manufactured, and support the whole shear force. As such, a rectangular shear key was found to be a suitable alternative to a circular shear key.

Taguchi Optimization of Rectangular-Type Shear Key. The optimized shape for the rectangular shear key was obtained using the Taguchi method. The assembly of the shear key and flange was also optimized. First, the effect of the gap between the shear key and the flange was examined. As shown in Fig. 7, when confirming the stress change of the shear key for the gap, the least stress was obtained with a fillet $(R=5 \mathrm{~mm})$ for the flange.

Table 9 shows the stress improvement ratio when optimizing the fillet of the shear key and flange.

$\mathrm{T}$ a b 1 e 9

\section{Stress as Fillet of the Shear Key}

\begin{tabular}{|c|c|}
\hline Item & Shear key \\
\hline Optimized model by Taguchi & $275.0 \mathrm{MPa}$ \\
\hline Optimized model $($ gap $=3.2 \mathrm{~mm})$ & $211.6 \mathrm{MPa}$ \\
\hline Improving ratio & $29.8 \%$ \\
\hline
\end{tabular}

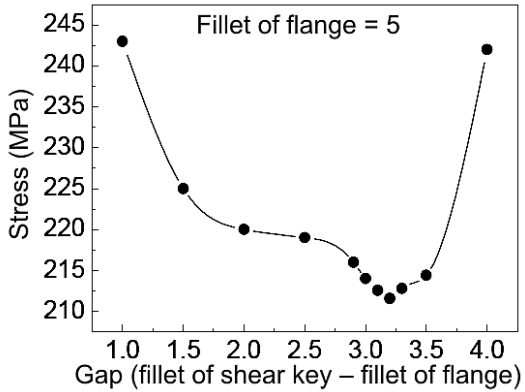

Fig. 7. Stress change of the shear key as gap.

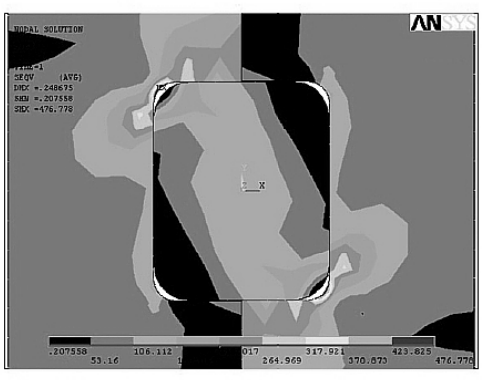

a

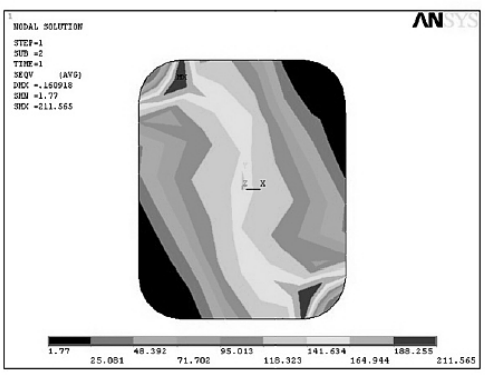

$\mathrm{b}$

Fig. 8. Analysis result of optimized shear key structure (a); analysis result of optimized shear key (b).

The FEA results for optimizing the fillet of the rectangular shear key are shown in Fig. 8.

Conclusions. This study optimized the shape of the shear key joining the TF coil structure of the KSTAR tokamak, and the results were as follows:

1. To optimize the shape of the shear key, the present study used an orthogonal array of an experimental design and the Taguchi method, which is a statistical design and quality technique. 
2. The design specifications with the least stress were obtained when using optimized circular and rectangular shear keys based on the Taguchi method.

3. The design variables for the circular shear key were independent, so 4 variables could be separately applied as design variables, which is advantageous.

4. A rectangular shear key was obtained by simultaneously considering the interaction between the key hole and aspect ratio.

5. From the FEA results, the stress of the circular shear key was more than twice lower compared to the rectangular shear key (circular/rectangular $=137 \mathrm{MPa} / 275 \mathrm{MPa}$ ). Thus, the circular shear key exhibited an advantage as regards shear force.

6. By adjusting the gap and fillet between the rectangular shear key and flange, the stress of the shear key was reduced by $29.8 \%$.

1. C. H. Choi, TF Coil Structure Design, Korea Basic Science Institute.

2. G. S. Lee, J. Kim, S. M. Hwang, et al., "The design of the KSTAR Tokamak," Fusion Eng. Des., 46, 405-411 (1999).

3. Y. W. Lee, H. J. Ahn, and Y. S. Chang, Global Structural Analysis of TF Magnet, Hyundai Heavy Industries Co., Ltd., Korea Basic Science Institute (2001).

4. B. J. Hamrock, B. O. Jacobson, and S. R. Schmid, Fundamentals of Machine Elements, McGraw-Hill, New York (1999).

5. J. E. Shigley and C. R. Mischke, Mechanical Engineering Design, 5th edition, McGraw-Hill (1989).

6. K. J. Bathe, Finite Element Procedures, Prentice-Hall (1996).

7. S. Erdin and V. L. Pokrovsky, "Oscillations of spherical and cylindrical shells," Int. J. Mod. Phys. B, 15, No. 23, 3099-3105 (2001).

8. G. Taguchi, Quality Engineering at Development \& Design Step, KISA (1991).

9. G. Taguchi and S. Chowdhury, Robust Engineering, Learn How to Boost Quality While Reducing Cost \& Time to Market, McGraw-Hill (1999).

10. L. Gaul and C. A. Brebbia, Computational Methods in Contact Mechanics IV, WIT Press (1999).

11. P. K. Maiti and D. Chowdhury, "Discrete solid-on-solid model of interface with bending rigidity: restricted and unrestricted step sizes," Int. J. Mod. Phys. B, 12, No. 14, 1531-1538 (1998).

12. R. D. Cook, D. S. Malkus, and M. E. Plesha, Concepts and Applications of Finite Element Analysis, 3rd edition, John Wiley \& Sons, New York (1989).

13. Y. D. Kwon, N. S. Goo, and B. S. Lim, "Resolution of defects in degenerated shell elements through modification of Gauss integration," Int. J. Mod. Phys. B, 17, No. 8-9, 1877-1883 (2003).

14. Y. D. Kwon, N. S. Goo, and T. H. Yun, "Non-conforming solid elements for the analysis of bending deformation of isotropic/orthotropic materials with the smallest D.O.F., Int. J. Mod. Phys. B, 17, No. 8-9, 1863-1869 (2003).

Received 03. 08. 2015 